\title{
Dental Fear and Patient Preference for Emergency Dental Treatment Among Adults in COVID-19 Quarantine Centers in Dammam, Saudi Arabia
}

\author{
Muhammad Nazir (D) \\ Khalid S Almulhim (D) ${ }^{2}$ \\ Ziyad AIDaamah (1D ${ }^{3}$ \\ Salman Bubshait ${ }^{3}$ \\ Mohammed Sallout ${ }^{3}$ \\ Salman AIGhamdi ${ }^{3}$ \\ Jehan Alhumaid'
}

'Department of Preventive Dental Sciences, College of Dentistry, Imam Abdulrahman Bin Faisal University, Dammam, 3 I44I, Eastern Province, Saudi Arabia; ${ }^{2}$ Department of Restorative Dental Sciences, College of Dentistry, Imam Abdulrahman Bin Faisal University, Dammam, 3I44I, Eastern Province, Saudi Arabia; ${ }^{3}$ College of Dentistry, Imam Abdulrahman Bin Faisal University, Dammam, 3|44I, Eastern Province, Saudi Arabia
Correspondence: Muhammad Nazir Tel +966-543569615

Email manazir@iau.edu.sa
Purpose: Dental fear is associated with the avoidance of dental visits and negative oral health outcomes. It is important to assess distribution of dental fear and preference for emergency dental treatment among adult population during COVID-19. Therefore, the purpose of this study was to evaluate dental fear and emergency dental treatment among adults in COVID-19 quarantine centers in Greater Dammam, Saudi Arabia.

Materials and Methods: Male and female adults $(\mathrm{N}=606)$ in quarantine centers for COVID19 participated in this cross-sectional study (June-July 2020). Dental Fear Survey was used to collect data on dental fear. The participants also provided their responses about emergency dental treatment/dental attendance patterns in addition to demographic information.

Results: The mean DFS score of the sample was $39.08 \pm 19.47$, and $23.1 \%$ of the participants were a little fearful and $22.6 \%$ were highly fearful. About $36.8 \%$ reported that they would prefer to visit a dental office in case of dental emergency mostly for dental pain and fractured tooth during the COVID-19 pandemic. Only 10.4\% of the participants reported visiting a dentist in less than 3 months, $35.8 \%$ in less than 6 months, $52.5 \%$ between 6 and 12 months and more, and $1.3 \%$ never visited the dentist. DFS scores significantly differed among participants who visited the dentist in less than 3 months $(31.86 \pm 14.57)$, less than 6 months $(37.70 \pm 18.57)$, between 6 and 12 months and more $(40.78 \pm 20.23)$, and never visited the dentist $(65.75 \pm 14.74)(\mathrm{P}<0.001)$. The timing of last dental visit $(\mathrm{P}<0.001)$, female gender $(\mathrm{P}$ $0.039)$, and dental pain $(\mathrm{P}<0.001)$ were the significant predictors of dental fear.

Conclusion: Dental fear was common among adults with a predilection for the female gender. Increased dental fear was significantly related to dental pain and reduced dental attendance. Only one-third of adults were willing to perform emergency dental visits.

Keywords: dental anxiety, emergency treatment, dental visits, pandemic

\section{Introduction}

Dental fear is a major problem for patients and dentists in dental practice ${ }^{1}$ and high dental fear is known to affect up to $21.3 \%$ of the adult population. ${ }^{2,3}$ The individuals with dental fear exhibit psychosocial and psychosomatic conditions and have higher irregular dental attendance than those without dental fear. ${ }^{1,4}$ Avoidance of regular dental care and cancellation and postponement of dental appointments can occur because of high dental fear. Even dental attendance among individuals with dental fear is associated with dental pain or problem. Thus, dental fear can negatively impact regular dental attendance, delay dental treatment, enhance treatment needs, and compromise oral health. ${ }^{5,6}$ 
The most common stimuli which elicit dental fear in dental practice arise from dental injections and drills. ${ }^{4}$ Besides, female gender, low income, low education, and unfavorable attitudes toward dentists are contributing factors associated with dental fear. ${ }^{3,7,8}$ Gender plays an important role in dental fear as females are more likely to report dental fear and fear of dental pain than males. ${ }^{3,7}$ Varying level of dental fear is reported in people with different educational qualifications. ${ }^{9}$ There is also evidence of a negative correlation between dental fear and education levels. ${ }^{3}$ Therefore, due to the multifactorial nature of dental fear, it is important that dentists should identify patients with dental fear, understand the underlying cause, and use appropriate dental fear management techniques.

In China, the cases of novel coronavirus (2019-nCoV) were reported in December 2019. ${ }^{10}$ The outbreak then spread to other countries, and the World Health Organization (WHO) declared it Public Health Emergency of International Concern on 30 January $2020 .{ }^{11}$ In February 2020, the WHO named the novel coronavirus (2019-nCoV) as Coronavirus Disease 2019 (COVID19). ${ }^{12}$ Since then, the COVID-19 has created anxiety, excessive fear, and depressive symptom due to high morbidity and mortality and economic meltdown. ${ }^{13}$ The COVID-19 pandemic also affected dental academic activities, dental practices, and dental practitioners including their fear of contamination and close contacts. ${ }^{14-16}$ Many people avoid visiting medical and dental care facilities due to the fear of the novel COVID-19 and its rapid transmission through human-to-human contact and in the form of droplets. ${ }^{10,17}$ A recent study in China reported a strong impact of COVID-19 pandemic on reduced utilization of emergency dental services. ${ }^{17}$

Dental fear is a common barrier to dental attendance and a contributor to poor oral health. Therefore, it is important to know the distribution and severity of dental fear among people during the COVID-19 pandemic. It is also critical to understand the types of emergency dental procedures that patients would seek during the pandemic. In addition, information about dental fear with regards to gender, education, income, and nationality can be valuable for preventive strategies. Therefore, the purpose of this study was to evaluate dental fear and emergency dental treatment among adults in COVID-19 quarantine centers in Greater Dammam, Saudi Arabia. The study also investigated the sources of oral health information/instructions during the pandemic.

\section{Materials and Methods}

Adult populations in quarantine centers for COVID-19 were invited to participate in this cross-sectional study. Ethical approval of the study (EA 202056) was obtained from the Scientific Research Unit at the College of Dentistry, Imam Abdulrahman Bin Faisal University, Dammam. Three quarantine centers in Dhahran, AlKhobar, and Dammam cities (Greater Dammam) were approached to obtain permission to conduct the study. The participants were recruited from these centers using a convenience sampling method. The subjects who wanted to voluntarily provide their responses were included in the study. The researchers explained the study details to the participants and answered if they had any queries about the research. Those participants who were willing to participate in the study provided their verbal informed consent and completed a self-administered questionnaire which was sent to them using an online link through their email accounts or WhatsApp numbers. Hard copies of written informed consent were not obtained from participants to minimize cross-infection due to COVID-19. In addition, written inform consent is not always required in questionnaire studies because of minimum risk to participants (EA 202056). This study was conducted in accordance with the Declaration of Helsinki. A sample of 683 was adequate to provide reliable information on dental fear among adults. Sample size for the study was calculated using a $95 \%$ confidence level, expected proportion $(\mathrm{P}=0.5)$, and total width of confidence interval $(\mathrm{W}=0.075)$. Sample size $=$ $\mathrm{N}=4 \mathrm{Z} \alpha 2 \mathrm{P}(1-\mathrm{P}) /(\mathrm{W} 2)=683$. Data collection was completed in 2 months (June-July 2020).

\section{Measures}

Dental Fear Survey (DFS) and the Modified Dental Anxiety Scale (MDAS) are commonly used instruments for the evaluation of dental fear/anxiety. A previous study showed that internal consistencies for MDAS (0.90-0.92) were lower than for DFS (0.96) in two samples of patients in addition to test-retest reliabilities for DFS (0.95) than for MDAS (0.94). ${ }^{18}$ Another study demonstrated a positive and significant correlation between DFS and MDAS, the Gatchel's Dental Fear Scale (G'sDFS), and the Visual Analog Scale. ${ }^{19}$ Therefore, the study used DFS to collect data on dental fear.

DFS evaluates dental fear by assessing behavioral, physiological, and cognitive situations specific to dental treatment procedures. The DFS instrument consists of 20 
items, which are grouped into avoidance, physiological arousal, and fears of specific stimuli/situations domains. ${ }^{20}$ There are eight items in the avoidance domain, five items in the physiological arousal domain, and seven items in the fears of specific stimuli/situations domain. A 5-point Likert scale is used for each item in DFS. ${ }^{4,20,21}$ The score in "avoidance" ranges from 8 to 40; in "physiological arousal" from 5 to 25 , and in "fears of specific stimuli/ situations" from 7 to 35 . The total score of DFS instrument ranges from 20 to 100 and a greater score indicates higher dental fear. ${ }^{22}$ DFS score $\leq 35$ is used to categorize participants into "not fearful", score between $\leq 36$ and $\leq 52$ into "a little fearful", and score $\geq 53$ in to "highly fearful/high dental fear". 23

Dental attendance patterns of the study participants were assessed by the questions that were taken from the World Health Organization's Oral Health Survey of Adults. ${ }^{24}$ These questions were about the timing and reasons for the last dental visit. In addition, there were some questions about visiting a dental office in case of a dental emergency during the COVID-19 pandemic. Dental conditions for dental emergency treatment included dental pain, facial swelling, tooth extraction, bleeding gums, dental trauma, dislodged crown, fractured tooth, fractured/dislodged restorations, and fractured prosthesis. The questionnaire was developed in English and then translated into the Arabic language. Pilot testing of English and Arabic versions of the questionnaires was conducted before final administration among study participants. Data of pilot testing were not included in the analysis of study results. Both versions of the questionnaires were administered among Arab and non-Arab study participants.

\section{Variables}

Dental fear was a dependent and continuous variable and age, gender, nationality, income, educational level, and dental attendance patterns were independent variables in the study. The relationship of these independent variables with dental fear was evaluated. The total score of DFS was calculated and participants were categorized into no fear, low fear, and high fear groups.

\section{Statistical Analysis}

The Statistical Package for the Social Sciences, version 22.0 for Windows (IBM SPSS Statistics for Windows, Armonk, NY: IBM Corp) was used to conduct statistical analyses. Descriptive statistics were calculated and presented in tables and graphs. The normality of dental fear and other continuous variables were assessed using the Kolmogorov-Smirnov test. As a result, independent sample $t$-test and one-way ANOVA test were performed for bivariate statistical analysis. Multiple linear regression analysis was used to evaluate the relationship between dental fear and independent variables. The significance level was set at $5 \%$ for all statistical tests.

\section{Results}

The study included data analysis of 606 male (59.4\%) and female $(40.6 \%)$ participants with a mean age of $30.49 \pm$ 12.01 years. The majority of participants were Saudi (94.6\%) and had college/university education (79.9\%) and middle/high monthly family income (79.7\%). The mean DFS score of the sample was $39.08 \pm 19.47$. The mean scores for domains of DFS included 15.20 \pm 8.51 for avoidance, $7.30 \pm 4.23$ for physiological arousal, and $16.58 \pm 8.83$ for fears of specific stimuli/situations. More than half the participants $(54.3 \%)$ were not fearful, $23.1 \%$ were a little fearful, and $22.6 \%$ were highly fearful.

Females demonstrated significantly higher dental fear $(41.17 \pm 17.94)$ than males $(37.65 \pm 20.34)(\mathrm{P}=0.029)$. A statistically significant difference in mean DFS score was also observed among participants who had pain or discomfort in teeth or mouth during the past 12 months $(42.57 \pm 20.54)$ than those without pain or discomfort $(34.74 \pm 17.11)(\mathrm{P}<$ 0.001). Nationality, level of education, monthly family income, medical problem, and negative dental experience showed no significant relationship with dental fear (Table 1).

Almost one-third of participants $(36.8 \%)$ reported that they would visit dental office in case of a dental emergency during the COVID-19 pandemic. Among those who were willing to perform emergency dental visits, dental pain $(36.6 \%)$, fractured tooth $(36.1 \%)$, fractured prosthesis $(34.2 \%)$, and facial swelling $(33.7 \%)$ were the most frequently reported dental conditions. Only $5.3 \%$ of the participants mentioned that they would visit a dental office in case of bleeding gums related emergency (Figure 1).

Regarding the timing of last dental visit, only $10.4 \%$ of the participants reported visiting the dentist in less than 3 months, $35.8 \%$ in less than 6 months, $52.5 \%$ between 6 and 12 months and more, and $1.3 \%$ never visited the dentist. Pain or trouble with teeth, gums or mouth was the most common reason for the last dental visit $(46.5 \%)$, followed by routine check-up/treatment $(24.3 \%)$, and treatment/follow-up treatment (19.8\%). Timing of last dental visit was significantly related to dental fear as statistically significant differences in DFS scores were observed among participants who visited 
Table I Bivariate Analysis: Sociodemographic Variables and Their Relationship with Dental Fear

\begin{tabular}{|c|c|c|c|}
\hline Study Variables & Frequency (\%) & Mean DFS & P-value \\
\hline \multicolumn{4}{|l|}{ Gender } \\
\hline Male & $360(59.4)$ & $37.65 \pm 20.34$ & 0.029 \\
\hline Female & $246(40.6)$ & $41.17 \pm 17.94$ & \\
\hline \multicolumn{4}{|l|}{ Nationality } \\
\hline Saudi & $573(94.6)$ & $38.79 \pm 19.61$ & 0.133 \\
\hline Non-Saudi & $33(5.4)$ & $44.03 \pm 16.23$ & \\
\hline \multicolumn{4}{|l|}{ Level of education } \\
\hline School education & $122(20.1)$ & $36.58 \pm 18.85$ & 0.113 \\
\hline College/University education & $484(79.9)$ & $39.71 \pm 19.61$ & \\
\hline \multicolumn{4}{|l|}{ Monthly family income } \\
\hline Low: less than $5000 \mathrm{SAR} /$ month & $123(20.3)$ & $39.43 \pm 21.68$ & 0.215 \\
\hline Middle: $500 \mathrm{I}-20,000 \mathrm{SAR} / \mathrm{month}$ & $315(52.0)$ & $37.86 \pm|7.9|$ & \\
\hline High: $20,000 \mathrm{SAR} / \mathrm{month}$ and above & $168(27.7)$ & $41.10 \pm 20.47$ & \\
\hline \multicolumn{4}{|l|}{ Medical problems } \\
\hline Yes & $79(13.0)$ & $40.66 \pm 19.39$ & 0.440 \\
\hline No & $527(87.0)$ & $38.84 \pm 19.49$ & \\
\hline \multicolumn{4}{|c|}{ Pain or discomfort in teeth or mouth during the past 12 months } \\
\hline Yes & $336(55.4)$ & $42.57 \pm 20.54$ & $<0.001$ \\
\hline No & $270(44.6)$ & $34.74 \pm 17.11$ & \\
\hline \multicolumn{4}{|l|}{ Negative dental experience in the past } \\
\hline Yes & $258(42.6)$ & $40.29 \pm 19.41$ & 0.186 \\
\hline No & $348(57.4)$ & $38.18 \pm 19.49$ & \\
\hline
\end{tabular}

the dentist in less than 3 months $(31.86 \pm 14.57)$, less than 6 months $(37.70 \pm 18.57)$, between 6 and 12 months and more $(40.78 \pm 20.23)$, and never visited the dentist $(65.75 \pm 14.74)$ $(\mathrm{P}<0.001)$. Data analysis showed similar results with avoidance and fear of specific stimuli/situations domains (Table 2). However, the physiological arousal domain score did not differ significantly. The study showed no significant relationship between reasons for the last dental visit and dental fear. The multiple linear regression model showed that the timing of last dental visit $(\mathrm{P}<0.001)$, female gender $(\mathrm{P}=0.039)$, and dental pain $(\mathrm{P}<0.001)$ were the significant predictors of dental fear after controlling for age, education level, and family income (Table 3 ).

Family and friends (62.5\%) and social media (57.6\%) were the most commonly reported sources of oral health instructions during the COVID-19 pandemic. On the other hand, only $0.70 \%$ indicated the dentist as a source of oral health instructions (Figure 2).

\section{Discussion}

The prevalence of dental fear was $45.7 \%$ in this sample of predominantly Saudi adults in quarantine centers. The mean
DFS score $(39.08 \pm 19.47)$ in the present study was slightly lower than what was reported in previous studies of Iranian patients $(41.16 \pm 15.96)^{25}$ and Turkish general population (41.6 \pm 17.2$)$ before COVID-19 pandemic. $^{3}$ On the other hand, mean DFS scores were lower in adult patients in Greek $(34.00 \pm 17.07)^{18}$ and Japan $(38.54 \pm 13.30) .{ }^{26}$ Moreover, lower estimates of DFS $(34.8 \pm 13.1)$ were also reported in a study of undergraduate students in Brazil. ${ }^{27}$ These differences in dental fear in different studies can be attributed to variations in study populations and study methodologies. In addition, the dental fear expression can be influenced by gender, age, previous dental experience, perception of dental clinic environment, and other psychological conditions. ${ }^{25,28}$

In the present study, females demonstrated significantly higher dental fear than male counterparts. The multiple linear regression analysis also showed a statistically significant correlation between female gender and dental fear. Similar findings of increased dental fear in the female gender were also reported in previous studies. ${ }^{18,25,26}$ Gender differences exist regarding biological, functional, cultural, and experiential factors that affect mood and anxiety. Females are more prone to high levels of stress, 


\section{Dental conditions for emergency dental visits}

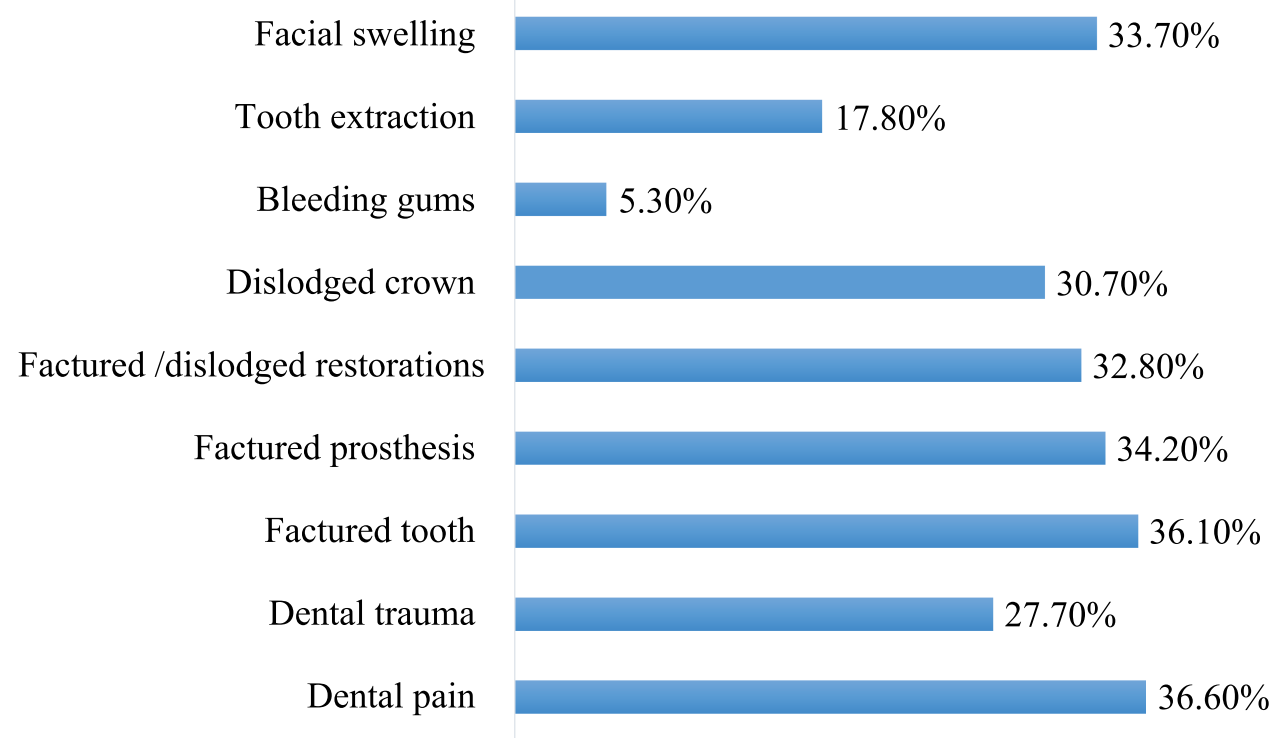

Figure I Distribution of participants' responses about dental conditions for emergency dental visits.

fear, anxiety disorder, phobia, and depression than males which may account for greater feelings of dental fear in females in the present study. ${ }^{29}$ Additionally, expectations of society for men to be strong may lead them to underreport their fear of dental fear. This may also explain why fear toward dental treatment/situation is less frequently reported in men than women. ${ }^{7}$

It is commonly believed that dental fear develops from an unpleasant or negative experience in previous dental visits. Negative dental experience may include severe pain/fright during a dental procedure or negative interactions between dentists and patients. ${ }^{28}$ As a result, patients may associate the dental practice with an unpleasant experience. It is known that the avoidance of dental treatment because of past negative dental experience is predictive of increased dental fear among patients. ${ }^{19}$ Several studies documented that past negative experience contributed to greater dental fear. ${ }^{9,25,30}$ The present study demonstrated higher dental fear among those participants who had past negative dental experience than those who did not have such an experience; however, the difference was not statistically significant. The use of a dental fear instrument has been recommended for quick and accurate assessment of dental fear among patients in addition to inquiring about the past dental experience and current dental visit for appropriate patient management. ${ }^{19}$ However, only a small percentage of dentists in Australia (3.7\%), ${ }^{31}$ and the UK $(20 \%)^{32}$ used a scale to screen patients with dental fear or anxiety.

Table 2 Relationship Between Timing of Dental Visits and Dental Fear Among Study Participants

\begin{tabular}{|c|c|c|c|c|c|}
\hline \multirow[t]{2}{*}{ Dental Fear } & \multicolumn{4}{|c|}{ Last Dental Visit } & \multirow[t]{2}{*}{ P-value } \\
\hline & $\begin{array}{c}\text { Less Than } 3 \\
\text { Months } \\
\text { Mean } \pm \text { SD }\end{array}$ & $\begin{array}{c}\text { Less Than } 6 \\
\text { Months } \\
\text { Mean } \pm \text { SD }\end{array}$ & $\begin{array}{c}\text { 6-12 Months and } \\
\text { More } \\
\text { Mean } \pm \text { SD }\end{array}$ & $\begin{array}{c}\text { Never } \\
\text { Visited } \\
\text { Mean } \pm \text { SD }\end{array}$ & \\
\hline Mean DFS score & $31.86 \pm 14.57$ & $37.70 \pm 18.57$ & $40.78 \pm 20.23$ & $65.75 \pm 14.74$ & $<0.001$ \\
\hline Avoidance score & $12.55 \pm 6.40$ & $14.53 \pm 8.13$ & $15.89 \pm 8.85$ & $26.75 \pm 7.71$ & $<0.001$ \\
\hline Physiological Arousal score & $6.25 \pm 3.0$ & $7.27 \pm 4.39$ & $7.48 \pm 4.30$ & $9.25 \pm 4.46$ & 0.105 \\
\hline $\begin{array}{l}\text { Fears of specific stimuli/situations } \\
\text { score }\end{array}$ & $13.05 \pm 6.85$ & $15.90 \pm 8.16$ & $17.41 \pm 9.27$ & $29.75 \pm 4.77$ & $<0.001$ \\
\hline
\end{tabular}


Table 3 Multiple Linear Regression Model: Relationship of Factors with Dental Fear Among Study Participants

\begin{tabular}{|l|c|c|c|c|c|}
\hline \multirow{2}{*}{ Variables } & \multicolumn{2}{|c|}{ Unstandardized Coefficients } & \multicolumn{2}{c|}{ Standardized Coefficients } & \multirow{2}{*}{ P-value } \\
\cline { 2 - 6 } & B & Std. Error & Beta & \multicolumn{2}{c|}{4} \\
\hline Timing of last dental visit & 4.65 & 1.11 & 0.17 & 2.06 & $<0.00 I^{*}$ \\
Female gender & 3.28 & 1.59 & 0.08 & $0.039 *$ \\
Dental pain & 7.22 & 1.56 & 0.18 & 4.62 & $<0.00 I^{*}$ \\
\hline
\end{tabular}

Note: *Statistically significant after controlling for age, education level, and monthly family income.

People with high dental fear tend to avoid or delay dental visits and many regularly cancel dental appointments. ${ }^{28}$ The time since last dental visit was a significant predictor of dental fear in the present study. The participants who never visited the dentist demonstrated the highest levels of dental fear whereas the lowest dental fear was found in adults who performed dental visits in less than 3 months. Avoidance, physiological arousal, and fear of specific stimuli or situations domains showed similar results regarding the timing of last dental attendance. In addition, a significant positive correlation was found between the timing of last dental visit and fear in a multiple linear regression analysis. These study findings are in accordance with previously published literature. $^{25,33,34}$ In a study of Australian residents, Armfield et al showed that people with high dental fear were more likely to have a longer duration since their last dental visit. ${ }^{34}$ Pohjola et al indicated that high dental fear was associated with irregular dental attendance among Finnish adults. ${ }^{33}$ Similarly, Saatchi et al observed greater dental fear among patients who performed irregular attendance than regular attendees in Iran. $^{25}$

More than half the sample in the present study reported dental pain or discomfort during the last 1 year, and dental fear was significantly higher in those with than without dental pain. The high occurrence of dental caries, periodontal disease, and other oral conditions may account for the high prevalence of dental pain in our sample. Dental pain was also a significant predictor of dental fear independent of age, gender, income, education, and timing of the last dental visit in the present study. Dental pain is

\section{Sources of oral health instructions during Covid 19 pandemic}

Others $1.50 \%$

\section{Social media}

Ministry of Health

Television/radio

Family and friends

$57.60 \%$

$\begin{aligned} \text { Ministry of Health } & 4.50 \% \\ \text { Television/radio } & 16 \% \\ \text { Family and friends } & 62.50 \% \\ \text { Dentist } & 0.70 \%\end{aligned}$

Figure 2 Distribution of participants' responses about sources of oral health instructions during COVID-19 pandemic. 
rooted in the etiology of the multifactorial problem of dental fear and there is a complex interplay between dental pain and dental fear as increased dental pain affects dental fear and heightened fear of dental treatment impacts dental pain. ${ }^{35}$ Strong role of genetics in dental fear and fear of pain was reported in a cohort study of family-based participants in the U.S. where a significant correlation was also observed between dental fear and fear of pain. ${ }^{36}$

Recently, a retrospective study reported that 1567 patients sought emergency dental services before the COVID-19 epidemic than 970 patients during the pandemic in Beijing, China. This revealed a $38.1 \%$ reduction in emergency dental care suggesting a strong impact of the COVID-19 epidemic on emergency dental care utilization. ${ }^{17}$ Another recent study of dentists in Iran also showed that $70 \%$ of the participants did not provide nonemergency dental treatment to patients during the COVID19 pandemic. ${ }^{37}$ In the present study, $36.8 \%$ of the adults reported that they would visit a dental office in case of a dental emergency during the COVID-19 pandemic and dental pain, fractured tooth, fractured prosthesis, and facial swelling were the most commonly reported dental conditions for emergency dental visits. Likewise, Guo et al identified pulpal or periapical lesions, followed by cellulitis/abscess, and dental trauma as the main reasons for emergency dental visits during the COVID-19 epidemic. ${ }^{17}$

The present study showed that only about one-quarter of patients attended dental office for emergency treatment during COVID-19 epidemic which reflects low uptake of oral care for emergency dental conditions. This avoidance of dental care due to dental fear is known to aggravate existing oral conditions, lead to vicious circle of dental fear, increase treatment needs, and further worsen oral health status. ${ }^{5,6}$ Despite the importance of proper oral care for the maintenance of optimal oral health, the avoidance of emergency dental treatment may occur because of anxiety, depression, morbidity and mortality associated with COVID-19. ${ }^{13}$

AlSadhan et al conducted a study on adults seeking dental care in public and private sectors in Riyadh, Saudi Arabia, and showed that dentist $(49.3 \%)$ was the main source of oral health care information, followed by television $(36.3 \%)$, books $(15 \%)$ and family $(12 \%) .{ }^{38}$ However, due to lockdowns as a result of the pandemic, family and friends $(62.5 \%)$, and social media $(57.6 \%)$ were the most common sources of oral health information in the present study. Less than $1 \%$ of participants indicated dentists as the source of oral health instruction which points out to a big interpersonal communication gap between dentists and their patients in Dammam. This study finding underscores the importance of using social media platforms in establishing strong dentist-patient communication for improved oral health awareness/education and positive patient oral health outcomes. The present study also observed the wide use of social media among adults for the acquisition of oral health information.

The use of a sensitive, reliable, and valid instrument in a large sample of adults provided robust evidence that filled the gap on dental fear, dental attendance, and sources of oral health information during the pandemic. However, there are certain limitations to the present study. The use of a convenience sample may compromise the validity of study findings. In addition, the study participants were mostly Saudi nationals and were from middle/high socioeconomic status who returned from abroad. Hence, the generalizability of study results to adults in the country should be avoided. Self-reported data in survey studies are less accurate than studies involving clinical examination. Moreover, a cross-sectional study design is also limited in drawing inferences about a causal relationship between independent variables and dependent variables.

\section{Conclusion}

Dental fear was common among adults during the COVID-19 pandemic with a considerable proportion demonstrating high dental fear. Almost one-quarter of participants indicated that they would visit a dental office in case of a dental emergency most frequently for dental pain and fractured tooth. Public health measures should be aimed at improving this low uptake of emergency oral care and avoiding further exacerbation of dental fear and oral problems. Female gender, dental pain, and reduced dental attendance were significantly and independently related to increased dental fear. Family and friends and social media were the most commonly reported sources of oral health instructions during the pandemic. Successful management of dental fear requires the assessment of the severity of dental fear and adoption of appropriate treatment approaches tailored to individual patients.

\section{Acknowledgments}

The authors thank administration of quarantine centers.

\section{Disclosure}

The authors report no conflicts of interest in this work. 


\section{References}

1. Berggren U, Meynert G. Dental fear and avoidance: causes, symptoms, and consequences. J Am Dent Assoc. 1984;109:247-251. doi:10.14219/jada.archive.1984.0328

2. Milgrom P, Fiset L, Melnick S, Weinstein P. The prevalence and practice management consequences of dental fear in a major US city. J Am Dent Assoc. 1988;116:641-647.

3. Firat D, Tunc EP, Sar V. Dental anxiety among adults in Turkey. J Contemp Dent Pract. 2006;7:75-82. doi:10.5005/jcdp-7-3-75

4. Quteish Taani DS. Dental anxiety and regularity of dental attendance in younger adults. J Oral Rehabil. 2002;29:604-608. doi:10.1046/ j.1365-2842.2002.00905.x

5. Armfield JM, Stewart JF, Spencer AJ. The vicious cycle of dental fear: exploring the interplay between oral health, service utilization and dental fear. BMC Oral Health. 2007;7:1. doi:10.1186/1472-6831-7-1

6. Armfield JM. What goes around comes around: revisiting the hypothesized vicious cycle of dental fear and avoidance. Community Dent Oral Epidemiol. 2013;41:279-287. doi:10.1111/ cdoe. 12005

7. Heft MW, Meng X, Bradley MM, Lang PJ. Gender differences in reported dental fear and fear of dental pain. Community Dent Oral Epidemiol. 2007;35:421-428. doi:10.1111/j.1600-0528.2006.00344.x

8. Doerr PA, Lang WP, Nyquist LV, Ronis DL. Factors associated with dental anxiety. J Am Dent Assoc. 1998;129:1111-1119. doi:10.14219/ jada.archive.1998.0386

9. Acharya S. Factors affecting dental anxiety and beliefs in an Indian population. J Oral Rehabil. 2008;35:259-267. doi:10.1111/j.13652842.2007.01777.x

10. Li Q, Guan X, Wu P, et al. Early transmission dynamics in Wuhan, China, of novel coronavirus-infected pneumonia. $N$ Engl $J$ Med. 2020;382:1199-1207. doi:10.1056/NEJMoa2001316

11. World Health Organization. Statement on the second meeting of the International Health Regulations (2005) Emergency Committee regarding the outbreak of novel coronavirus (2019-nCoV). Geneva, Switzerland: World Health Organization; 2020.

12. Zu ZY, Jiang MD, Xu PP, et al. Coronavirus disease 2019 (COVID-19): a perspective from China. Radiology. 2020;296:E15E25. doi:10.1148/radiol.2020200490

13. Wang C, Pan R, Wan X, et al. Immediate psychological responses and associated factors during the initial stage of the 2019 coronavirus disease (COVID-19) epidemic among the general population in China. Int J Environ Res Public Health. 2020;17:1729. doi:10.3390/ ijerph17051729

14. Gambarini G, Di Nardo D, Obino FV, et al. Academic dental activities and COVID-19 pandemic. J Contemp Dent Pract. 2020;21:598.

15. Gambarini G, Galli M, Gambarini E, et al. Fine aerosols and perceived risk of COVID-19 among Italian dental practitioners: an experimental survey. J Contemp Dent Pract. 2020;21:599-603. doi:10.5005/jp-journals-10024-2850

16. Gambarini E, Galli M, Di Nardo D, et al. A survey on perceived COVID-19 risk in dentistry and the possible use of rapid tests. J Contemp Dent Pract. 2020;21:718-722. doi:10.5005/jp-journals $-10024-2851$

17. Guo H, Zhou Y, Liu X, Tan J. The impact of the COVID-19 epidemic on the utilization of emergency dental services. J Dent Sci. 2020;15:564-567. doi:10.1016/j.jds.2020.02.002

18. Coolidge T, Arapostathis KN, Emmanouil D, et al. Psychometric properties of Greek versions of the Modified Corah Dental Anxiety Scale (MDAS) and the Dental Fear Survey (DFS). BMC Oral Health. 2008;8:29. doi:10.1186/1472-6831-8-29

19. Heaton LJ, Carlson CR, Smith TA, Baer RA, de Leeuw R. Predicting anxiety during dental treatment using patients'self-reports: less is more. J Am Dent Assoc. 2007;138:188-195. doi:10.14219/jada. archive. 2007.0135
20. Kleinknecht RA, Thorndike RM, McGlynn FD, Harkavy J. Factor analysis of the dental fear survey with cross-validation. J Am Dent Assoc. 1984;108:59-61. doi:10.14219/jada.archive.1984.0193

21. Kleinknecht RA, Klepac RK, Alexander LD. Origins and characteristics of fear of dentistry. J Am Dent Assoc. 1973;86:842-848. doi:10.14219/jada.archive.1973.0165

22. Cesar J, de Moraes AB, Milgrom P, Kleinknecht RA. Cross validation of a Brazilian version of the dental fear survey. Community Dent Oral Epidemiol. 1993;21:148-150. doi:10.1111/j.1600-0528.1993. tb00740.x

23. Oliveira MA, Bendo CB, Paiva SM, Vale MP, Serra-Negra JM. Determining cut-off points for the dental fear survey. Sci World J. 2015;2015:983564. doi:10.1155/2015/983564

24. World Health Organization. Oral health surveys: basic methods. Geneva, Switzerland: World Health Organization; 2013.

25. Saatchi M, Abtahi M, Mohammadi G, Mirdamadi M, Binandeh ES. The prevalence of dental anxiety and fear in patients referred to Isfahan Dental School, Iran. Dent Res J. 2015;12(3):248-253.

26. Ogawa M, Sago T, Furukawa $H$. The reliability and validity of the Japanese version of the modified dental anxiety scale among dental outpatients. ScientificWorldJournal. 2020;2020:8734946. doi: $10.1155 / 2020 / 8734946$

27. Oliveira MA, Vale MP, Bendo CB, Paiva SM, Serra-Negra JM. Dental fear survey: a cross-sectional study evaluating the psychometric properties of the Brazilian Portuguese version. Sci World J. 2014;2014:725323. doi:10.1155/2014/725323

28. Armfield JM, Heaton LJ. Management of fear and anxiety in the dental clinic: a review. Aust Dent J. 2013;58:390-407. doi:10.1111/ adj. 12118

29. Altemus M, Sarvaiya N, Neill Epperson C. Sex differences in anxiety and depression clinical perspectives. Front Neuroendocrinol. 2014;35:320-330. doi:10.1016/j.yfrne.2014.05.004

30. Fayad MI, Elbieh A, Baig MN, Alruwaili SA. Prevalence of dental anxiety among dental patients in Saudi Arabia. J Int Soc Prev Community Dent. 2017;7:100-104. doi:10.4103/jispcd. JISPCD 1917

31. Armfield $\mathrm{JM}$, Mohan H, Luzzi L, Chrisopoulos S. Dental anxiety screening practices and self-reported training needs among Australian dentists. Aust Dent J. 2014;59:464-472. doi:10.1111/adj.12211

32. Dailey YM, Humphris GM, Lennon MA. The use of dental anxiety questionnaires: a survey of a group of UK dental practitioners. $\mathrm{Br}$ Dent J. 2001;190:450-453. doi:10.1038/sj.bdj.4801000

33. Pohjola V, Lahti S, Vehkalahti MM, Tolvanen M, Hausen $H$. Association between dental fear and dental attendance among adults in Finland. Acta Odontol Scand. 2007;65:224-230. doi:10.1080/ 00016350701373558

34. Armfield JM, Spencer AJ, Stewart JF. Dental fear in Australia: who's afraid of the dentist? Aust Dent J. 2006;51:78-85. doi:10.1111/ j.1834-7819.2006.tb00405.x

35. Bernstein DA, Kleinknecht RA, Alexander LD. Antecedents of dental fear. J Public Health Dent. 1979;39:113-124. doi:10.1111/j.17527325.1979.tb02932.x

36. Randall CL, Shaffer JR, McNeil DW, et al. Toward a genetic understanding of dental fear: evidence of heritability. Community Dent Oral Epidemiol. 2017;45:66-73. doi:10.1111/cdoe.12261

37. Ahmadi H, Ebrahimi A, Ghorbani F. The impact of COVID-19 pandemic on dental practice in Iran: a questionnaire-based report. BMC Oral Health. 2020;20:354. doi:10.1186/s12903-020-01341-x

38. AlSadhan SA, Darwish AG, Al-Harbi N, Al-Azman A, Al-Anazi H. Cross-sectional study of preventive dental knowledge among adult patients seeking dental care in Riyadh, Saudi Arabia. Saudi J Dent Res. 2017;8:52-57. doi:10.1016/j.sjdr.2016.04.005 


\section{Publish your work in this journal}

Patient Preference and Adherence is an international, peer-reviewed, open access journal that focusing on the growing importance of patient preference and adherence throughout the therapeutic continuum. Patient satisfaction, acceptability, quality of life, compliance, persistence and their role in developing new therapeutic modalities and compounds to optimize clinical outcomes for existing disease states are major areas of interest for the journal. This journal has been accepted for indexing on PubMed Central. The manuscript management system is completely online and includes a very quick and fair peer-review system, which is all easy to use. Visit http:// www.dovepress.com/testimonials.php to read real quotes from published authors. 